\title{
Brain profiling in murine colitis and human epilepsy reveals neutrophils and TNFa as mediators of neuronal hyperexcitability
}

\author{
Sarah E. Barnes ${ }^{1}$, Kristy A. Zera², Geoffrey T. Ivison ${ }^{1,3}$, Marion S. Buckwalter ${ }^{2}$ and Edgar G. Engleman ${ }^{1 *}$ (D)
}

\begin{abstract}
Background: Patients with chronic inflammatory disorders such as inflammatory bowel disease frequently experience neurological complications including epilepsy, depression, attention deficit disorders, migraines, and dementia. However, the mechanistic basis for these associations is unknown. Given that many patients are unresponsive to existing medications or experience debilitating side effects, novel therapeutics that target the underlying pathophysiology of these conditions are urgently needed.

Methods: Because intestinal disorders such as inflammatory bowel disease are robustly associated with neurological symptoms, we used three different mouse models of colitis to investigate the impact of peripheral inflammatory disease on the brain. We assessed neuronal hyperexcitability, which is associated with many neurological symptoms, by measuring seizure threshold in healthy and colitic mice. We profiled the neuroinflammatory phenotype of colitic mice and used depletion and neutralization assays to identify the specific mediators responsible for colitis-induced neuronal hyperexcitability. To determine whether our findings in murine models overlapped with a human phenotype, we performed gene expression profiling, pathway analysis, and deconvolution on microarray data from hyperexcitable human brain tissue from patients with epilepsy.
\end{abstract}

Results: We observed that murine colitis induces neuroinflammation characterized by increased pro-inflammatory cytokine production, decreased tight junction protein expression, and infiltration of monocytes and neutrophils into the brain. We also observed sustained neuronal hyperexcitability in colitic mice. Colitis-induced neuronal hyperexcitability was ameliorated by neutrophil depletion or TNFa blockade. Gene expression profiling of hyperexcitable brain tissue resected from patients with epilepsy also revealed a remarkably similar pathology to that seen in the brains of colitic mice, including neutrophil infiltration and high TNFa expression.

Conclusions: Our results reveal neutrophils and TNFa as central regulators of neuronal hyperexcitability of diverse etiology. Thus, there is a strong rationale for evaluating anti-inflammatory agents, including clinically approved TNFa inhibitors, for the treatment of neurological and psychiatric symptoms present in, and potentially independent of, a diagnosed inflammatory disorder.

Keywords: Colitis, Inflammatory bowel disease, Epilepsy, Neuronal hyperexcitability, Neutrophils, TNFa

\footnotetext{
* Correspondence: edgareng@stanford.edu

${ }^{1}$ Department of Pathology, Stanford University, Stanford, CA, USA

Full list of author information is available at the end of the article
} 


\section{Background}

Patients with chronic inflammatory conditions frequently experience neurological and psychiatric complications including epilepsy, depression, attention deficit and hyperactivity disorders, migraines, and dementia [17]. A meta-analysis of data from $>25$ million individuals revealed associations between several autoinflammatory conditions and psychiatric disorders [1], and a retrospective population-level study found that the risk of epilepsy was increased almost fourfold in patients diagnosed with an autoimmune disorder [8]. Our lack of understanding of the mechanisms underlying these disorders and their neuropsychiatric complications makes it very difficult to identify which drugs will be most helpful for individual patients. Furthermore, psychiatric and neurological medications frequently produce disruptive and debilitating side effects such as cognitive impairment, sedation, exacerbation of other neurological and psychiatric symptoms, and sexual dysfunction $[9,10]$. These severe side effects combined with the large number of patients who do not respond to existing therapies provide a strong rationale to examine the mechanistic connection between peripheral inflammation and the development of neurological symptoms. Given that $4.5 \%$ of Americans suffer from an autoinflammatory disease [11], strategies to protect this population from developing neurological complications, as well as treat them, are urgently needed.

There are many hypotheses as to why peripheral inflammatory disorders and neurological conditions cooccur; however, there have been few mechanistic studies demonstrating a causal relationship, and investigations of these mechanisms have yielded contradictory results [12-18]. Other studies have utilized models of inflammation induced by large doses of nonspecific stimuli such as lipopolysaccharide (LPS), which do not closely mimic human disease [19-24]. Furthermore, neuroinflammation can exist in patients with neurological disorders who do not have a diagnosed autoinflammatory disease [25-29]. Because the vast majority of studies investigating the occurrence and impact of neuroinflammation on brain function have utilized models of primary neurological disease, it is difficult to uncouple the role of the primary neurological pathology from that of inflammation. To more clearly understand the mechanisms by which peripheral inflammatory disease causes neurological symptoms, it is therefore necessary to employ models of peripheral inflammation in which the brain is not initially involved.

Because intestinal disorders such as inflammatory bowel disease (IBD) are robustly associated with neurological symptoms $[2,4,8,30-42]$, we used three different mouse models of colitis to investigate the impact of peripheral inflammatory disease on the brain. We focused on measurements of neuronal excitability, since many neurological and psychiatric symptoms are associated with neuronal hyperexcitability.

Our experiments show that neuroinflammation and neuronal hyperexcitability develop in all three colitis models as a consequence of TNF $\alpha$-secreting neutrophils that infiltrate the brain. Moreover, we corroborated our findings in resected brain tissue from patients with epilepsy who had no known peripheral inflammatory disease, suggesting that TNF $\alpha$-mediated neuroinflammation contributes to neuronal hyperexcitability of diverse etiology.

\section{Methods}

\section{Animals}

C57BL/6J, $R a g 2^{-1-}$, and CCR2 $2^{\text {RFP/RFP }}$ mice were obtained

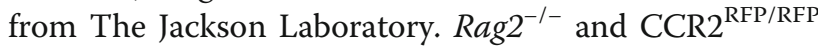
mice were then bred in-house at the Stanford Blood Center. Mice were age- and sex-matched for experiments. Experiments were conducted on mice between the ages of 6-8 weeks.

\section{Seizure threshold measurements}

Individual mice were placed in an airtight chamber. Using a syringe pump, 10\% flurothyl (Sigma Aldrich, $\# 287571$ ) in ethanol was administered at a rate of $100 \mu \mathrm{L} / \mathrm{min}$ onto a filter paper placed inside of the chamber, causing the flurothyl to evaporate within the chamber. Latency to both seizure onset and seizure generalization were measured. Seizure onset was noted as the first myoclonic jerk. Seizure generalization was noted as the first loss of posture.

\section{Colitis}

We utilized three murine colitis models. For acute DSS-induced colitis, mice were given 3\% DSS (Hardman Chemicals, or $3.5 \%$ from TdB Labs) in drinking water for 6 days, followed by 9 days of regular drinking water. For chronic DSS-induced colitis, this cycle was repeated two more times with an additional 7day break between cycles. For TCT-induced colitis, $\mathrm{CD}^{+} \mathrm{T}$ cells were enriched from $\mathrm{C} 57 \mathrm{BL} / 6 \mathrm{~J}$ spleens. Enriched cells were then FACS-sorted to obtain naïve $\mathrm{CD}^{+} \mathrm{T}$ cells $\left(\mathrm{CD} 45^{+} \mathrm{CD} 4^{+} \mathrm{CD} 45 \mathrm{RB}^{\text {hi }} \mathrm{CD} 25^{\text {lo }}\right)$ and Tregs $\left(\mathrm{CD} 45^{+} \mathrm{CD} 4^{+} \mathrm{CD} 45 \mathrm{RB}^{\mathrm{lo}} \mathrm{CD} 25^{\mathrm{hi}}\right)$. Experimental Rag $2^{-1-}$ mice received 500,000 naïve $\mathrm{CD}^{+} \mathrm{T}$ cells, and control mice received 500,000 naïve $\mathrm{CD}_{4}^{+} \mathrm{T}$ cells in addition to 100,000 Tregs.

\section{Murine tissue harvesting and processing}

Mice were anesthetized using isoflurane and then perfused with a minimum of $10 \mathrm{~mL}$ PBS, until the liver was fully perfused. Brains were harvested and excluded if perfusion was incomplete. A GentleMACS dissociator 
was used to homogenize brains in complete RPMI containing $1 \mathrm{mg} / \mathrm{mL}$ collagenase IV (Worthington Biochemical, \#LS004188). Brains were further digested by shaking inside of a $37^{\circ} \mathrm{C}$ incubator for $30 \mathrm{~min}$. The tissue was passed through a $70-\mu \mathrm{m}$ filter and washed in complete RPMI. Cells were separated using a 30\% Percoll (GE Healthcare, \#17089101) gradient and washed again in complete RPMI.

\section{Flow cytometry}

Single-cell suspensions were generated from harvested tissue. Cells were washed in PBS and then stained with 1:1000 Fc blocker and Live/Dead Aqua in PBS for $10 \mathrm{~min}$ at $4^{\circ} \mathrm{C}$. At this point, cells were either stained or fixed in $2 \%$ paraformaldehyde for $10 \mathrm{~min}$ at $4^{\circ} \mathrm{C}$ and stained the following day. For intracellular stains, cells were fixed and permeabilized using the Foxp3/Transcription Factor Staining Buffer Kit (eBioscience) prior to staining. Cells were washed in FACS buffer (PBS + 10\% FBS + 1mM EDTA) and stained using fluorescently labeled antibodies for 20 min at $4^{\circ} \mathrm{C}$. Cells were analyzed using a BD LSR Fortessa or BD FACS Canto.

\section{In vivo labeling of border-associated leukocytes}

Mice were anesthetized using isoflurane and then retroorbitally injected with $7.5 \mu \mathrm{g}$ of fluorescently labeled $\alpha$ CD45 antibody in PBS. Three minutes later, mice were immediately perfused with a minimum of $10 \mathrm{~mL}$ PBS, until the liver was fully perfused. Single-cell suspensions were generated from harvested brains and used for flow cytometry, and tissue sections were obtained for immunofluorescence. Cells were stained ex vivo with an $\alpha-$ CD45 antibody attached to a different fluorophore. Cells that were labeled with both antibodies were deemed border-associated, and cells that were labeled only with the ex vivo-administered antibody were deemed parenchymal.

\section{Protein and transcript quantification}

Plasma was obtained by collecting blood retro-orbitally with heparin capillary tubes into plasma microtainer tubes. Tubes were spun at 6000rpm for $6 \mathrm{~min}$. Plasma cytokine levels were measured using a cytokine bead array (BD Biosciences). To measure transcript levels, RNA was obtained from perfused, flash-frozen brains. Fast SYBR Green PCR mix (Applied Biosystems) and the 7900 HT real-time PCR instrument were used to conduct qRT-PCR.

\section{Immunohistochemistry and H\&E staining}

Mice were sedated using isoflurane and then perfused with PBS. Brains were collected and drop-fixed in $2 \%$ paraformaldehyde overnight at $4^{\circ} \mathrm{C}$. They were preserved in $30 \%$ sucrose at $4^{\circ} \mathrm{C}$. A freezing microtome (Microm HM430) was used to collect $40-\mu \mathrm{m}$ sections, which were stored in a cryoprotectant medium (30\% glycerin, $30 \%$ ethylene glycol, $40 \% 0.5 \mathrm{M}$ sodium phosphate buffer) at $20^{\circ} \mathrm{C}$. A standard immunohistochemistry protocol was performed to stain free-floating sections. Sections were blocked with $3 \%$ rabbit serum for $1 \mathrm{~h}$. The tissue was then incubated at $4^{\circ} \mathrm{C}$ overnight in primary $\alpha$-CD68 antibody (rat, 1:1000, BioRad MCA1957S). Tissue was incubated for $1 \mathrm{~h}$ in secondary rabbit $a$-rat IgG antibody (1:500, Vector Laboratories, \#BA-4001). Tissue was then treated with Avidin-Biotin Complex solution (Vector Laboratories, \#PK-6100) for $1 \mathrm{~h}$ and treated for 5 min with filtered DAB solution (Sigma Aldrich, \#D5905). Sections were mounted onto glass slides, air-dried overnight, and coverslipped with Entellan (Electron Microscopy Sciences 14,800). Quantification of area stained by CD68 was performed on 2 sections per brain for the cortex and 1 section per brain for the hippocampus by a researcher blinded to treatment groups using ImageJ software (National Institutes of Health). For in vivo

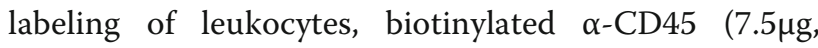
BioLegend \#103104) was administered in vivo with a secondary streptavidin-488 stain on tissue sections (1: 200, Thermo Fisher \#32354) and a pre-conjugated CD45-PE antibody (1:500, BD Biosciences \#561087) was used for ex vivo staining. For H\&E staining, brains were harvested as previously described, fixed in $2 \%$ paraformaldehyde overnight, and then stored in $70 \%$ ethanol. H\&E staining was performed by the Stanford Pathology Department Histology Services Core. For both IHC and H\&E, slides were imaged using a Keyence BZ-X700 microscope.

\section{Cellular depletion and cytokine neutralization}

Neutrophils were depleted by injecting mice intraperitoneally once daily with $500 \mu \mathrm{g} \alpha$-Ly6G antibody (clone 1A8, Bio X Cell) from days 6 to 14 after the onset of DSS treatment. Control mice received $500 \mu \mathrm{g}$ isotype control IgG2A (clone 2A8, Bio X Cell) according to the same treatment schedule. Monocytes were depleted by injecting mice retro-orbitally once daily with $200 \mu \mathrm{L}$ clodronate liposomes (Clodrosome) from days 6 to 14 after the onset of DSS treatment. Control mice received $200 \mu \mathrm{L}$ of PBS liposomes (Clodrosome) according to the same treatment schedule. TNF $\alpha$ was neutralized by injecting mice intraperitoneally once daily with $500 \mu \mathrm{g} \alpha$ TNF $\alpha$ antibody (clone XT3.11, Bio X Cell) from days 6 to 14 after the onset of DSS treatment. Control mice received $500 \mu \mathrm{g}$ isotype control IgG1 (clone HRPN, Bio X Cell). Treatment schedules were determined using longitudinal analysis of immune cell frequencies in the peripheral blood of colitic mice. 
Deconvolution, gene expression, and pathway analysis Agilent feature extraction files were processed using the Significance Analysis of Microarrays (SAM) R package [43]. Deconvolution was performed using CIBERSORTx [44]. PCA was performed using the Scikit-Learn PCA package for Python [45]. Differentially regulated genes were identified as having $p$-value $<0.05$ and $\log 2$ (fold change) $>1$. Gene ontology analysis was performed using the Gene Ontology Resource from the GO Consortium. Pathway analysis was performed using Enrichr $[46,47]$, and network analysis was performed using Cytoscape [48]. A $p$-value $<0.05$ was used to determine significant overlap between upregulated genes and predefined gene sets from the Kyoto Encyclopedia of Genes and Genomes (KEGG).

\section{Statistical analysis}

Unless otherwise specified, experimental data were analyzed using the Mann-Whitney $U$ test. For seizure threshold experiments, measurements were acquired and pooled over 3-4 days. Two-way ANOVAs were used to identify differences in measurement day as well as experimental treatment. Simple linear regressions were calculated to determine goodness of fit and statistically significant slopes. Longitudinal body weight measurements were compared using the Holm-Sidak method for performing multiple $t$-tests. Results are reported as mean with individual data points or mean \pm SEM: $p<0.05={ }^{*} ; p<0.01={ }^{* * *} ; p<0.001={ }^{* * * *} ; p<$ $0.0001=* \cdots *$. All statistics were calculated using Prism (GraphPad Software).

\section{Results}

Acute and chronic colitis cause a sustained reduction in seizure threshold

Our studies utilized three mouse colitis models, each of which is known to recapitulate various aspects of IBD: acute dextran sodium sulfate (DSS)-induced colitis (Fig. 1a, b), chronic DSS-induced colitis (Fig. 1a), and T cell transfer (TCT)-induced colitis (Fig. 1c). DSS impairs epithelial barrier function within the gut, resulting in the entry of intestinal microorganisms into the lamina propria and subsequent induction of innate and adaptive immune responses [49]. Although DSS has not been shown to enter the brain [50], we also utilized the TCTinduced colitis model to confirm that changes in seizure threshold were due to inflammation rather than any direct effects of DSS on the brain. In this model, regulatory $\mathrm{T}$ cell (Treg)-depleted naïve $\mathrm{CD} 4^{+} \mathrm{T}$ cells are retroorbitally transferred into Rag2 ${ }^{-/-}$mice, which lack B and $\mathrm{T}$ cells; control mice receive naïve $\mathrm{CD}^{+} \mathrm{T}$ cells in addition to Tregs. In the absence of Tregs, naïve $\mathrm{CD} 4^{+}$ $\mathrm{T}$ cells mount an immune response targeting the intestinal microbiota, resembling that of patients with IBD [49].

To measure neuronal hyperexcitability in each of the IBD models, we measured seizure threshold in response to flurothyl, a $\gamma$-aminobutyric acid (GABA) receptor antagonist. The dosage of flurothyl required to induce a seizure is inversely proportional to neuronal excitability; mice with hyperexcitability display reduced seizure thresholds [51]. Flurothyl was chosen for these experiments for three reasons: (1) it is administered via inhalation, which allows for control of dosing and limits mortality; (2) it is not metabolized and has no known direct influences on the immune response; and (3) unlike transgenic spontaneous seizure models, confounding effects of genetic mutations on immune responses and seizure-induced inflammation are avoided. We measured both the time to the first myoclonic jerk (latency to seizure onset) and the time to loss of posture (latency to seizure generalization), indicating that the seizure has spread widely throughout the brain. Regardless of the modality of colitis induction, mice with colitis displayed reduced latency to seizure onset and generalization compared to healthy mice (Fig. 1d, e). Notably, seizure onset and generalization continued to be more rapid in mice with acute colitis even after 30 days following the onset of acute colitis (Fig. 1f), indicating a long-lasting neuroexcitatory phenotype following acute DSS.

\section{Colitis induces monocyte and neutrophil infiltration of the brain, increased expression of neuroinflammatory cytokines, and decreased expression of tight junction proteins, but minimal microglial activation}

In support of the possibility that colitis-associated inflammatory factors contribute to neuroinflammation, we observed increased plasma concentrations of TNF $\alpha$, MCP-1/CCL2, IL-6, and IFN $\gamma$ in colitic mice (Fig. 2a, b), as well as increased transcription of $T n f, I l 1 b$, and Il6 in their brains (Fig. 2c). We also observed increased transcription of the adhesion molecule VCAM-1 (Vcam1), a marker of vascular neuroinflammation, and decreased transcription of the tight junction proteins ZO-1 (Tjp1) and claudin-5 (Cldn5) in the brains of colitic mice, indicative of blood-brain barrier (BBB) disruption (Fig. 2d). Transcription of Tnf, Il1b, and Il6 each correlated with decreased transcription of Tjp1, but not $C l d n 5$, suggesting that these cytokines may reduce BBB integrity via ZO-1 downregulation (Supplemental Figure 1). Transcription of Tnf, Illb, Il6, and Vcam1 all remained elevated, and Tjp1 and Cldn5 remained decreased, for 21 days following initiation of DSS treatment (beyond the point at which plasma cytokine concentrations had returned to baseline), further indicating that acute colitis induces a sustained neuroinflammatory response. 


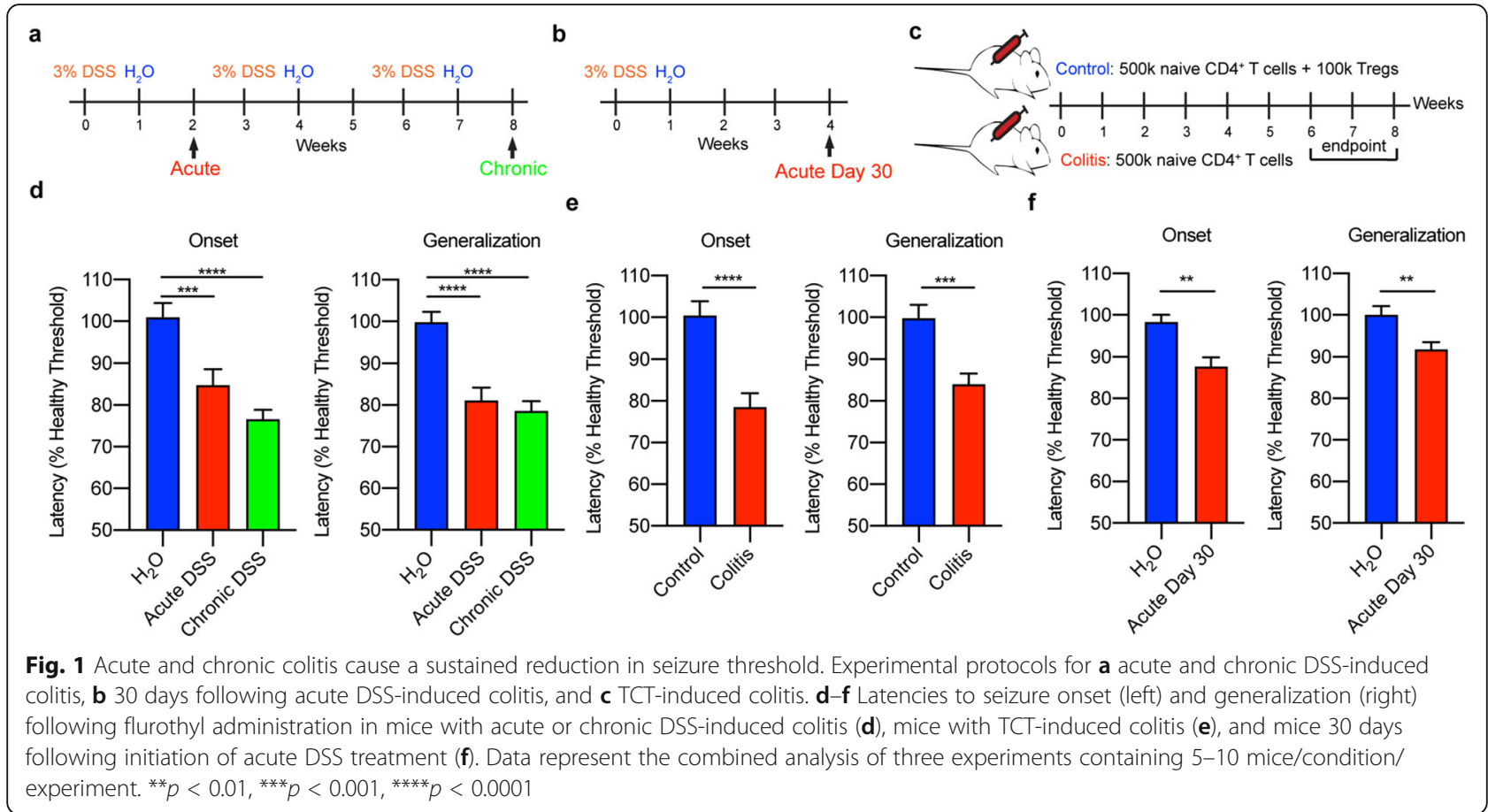

Because microglia are known to play a central role in neuroinflammation $[22,24,52-56]$, we characterized these brain-resident myeloid cells using immunohistochemistry and flow cytometry. However, we found no evidence of microglia activation in colitic mice, as reflected by unchanged CD68 expression in the cortex and hippocampus (Fig. 2e, f), reduced microglia frequency (likely attributable to infiltrating cells, Fig. 2g), and no increases in microglial CD45, TNF $\alpha$, or MHCII expression (Fig. 2h). Based on the increased transcription of the vascular adhesion molecule VCAM-1 in the brains of colitic mice (Fig. 2d), we hypothesized that peripheral immune cells adhered to brain vasculature and/ or infiltrated the brains of colitic mice. Flow cytometric analysis revealed increased frequencies of monocytes and neutrophils in the brains of colitic mice (Fig. 2i, j), but no meaningful changes in the frequencies of other immune cells (Supplemental Figure 2). Frequencies of monocytes and neutrophils remained elevated 30 days following the onset of acute colitis, further indicating that acute colitis induced a sustained neuroinflammatory response (Fig. 2k). We observed a small increase in $\mathrm{T}$ cell frequency in mice with TCT-, but not DSS-, induced colitis (Fig. 2j). Despite this increase, T cells were $<1 \%$ of total leukocytes, suggesting minimal involvement of these cells in the colitis-induced neuroinflammatory process.

To determine the location of these cells in the brain, we retro-orbitally injected mice with a fluorescently labeled $\alpha$-CD45 antibody; cells in the border regions (vasculature, perivascular spaces, ventricles, and meninges), but not the parenchyma, were labeled with the $\alpha$ CD45 antibody [55]. Using flow cytometry, we observed that almost all the monocytes and neutrophils in the brains of healthy control mice stained positive with the $\alpha-C D 45$ antibody, indicating that they were in border regions (Fig. 2l, Supplemental Figure 4). By contrast, roughly half of the monocytes and neutrophils present in the brains of colitic mice did not stain with the $\alpha$ CD45 antibody, indicating that they were located in the parenchyma. Using an H\&E stain, we observed leukocytes in both the parenchyma-which does not normally contain leukocytes-and border regions of the hippocampus and cortex in colitic mice (Fig. 2m).

\section{Neutrophils, but not monocytes, contribute to neuronal hyperexcitability following acute colitis via TNFa}

We next investigated the roles of monocytes and neutrophils in colitis-induced neuronal hyperexcitability by measuring seizure threshold following depletion of one or the other of these cell types. Monocyte depletion using clodronate had no impact on seizure threshold following acute DSS-induced colitis (Fig. 3a) despite significant depletion (Supplemental Figure 3a-b). Additionally, there was no change in seizure threshold in colitic $\mathrm{CCR} 2^{\mathrm{RFP} / \mathrm{RFP}}$ mice, in which the $\mathrm{Ccr} 2$ locus is replaced with RFP, impairing monocyte migration (Fig. 3b). $\mathrm{CCR} 2^{\mathrm{RFP} /+}$ mice were used as controls. This finding confirms that monocytes do not play a major pathogenic role in colitis-induced neuronal hyperexcitability. By 


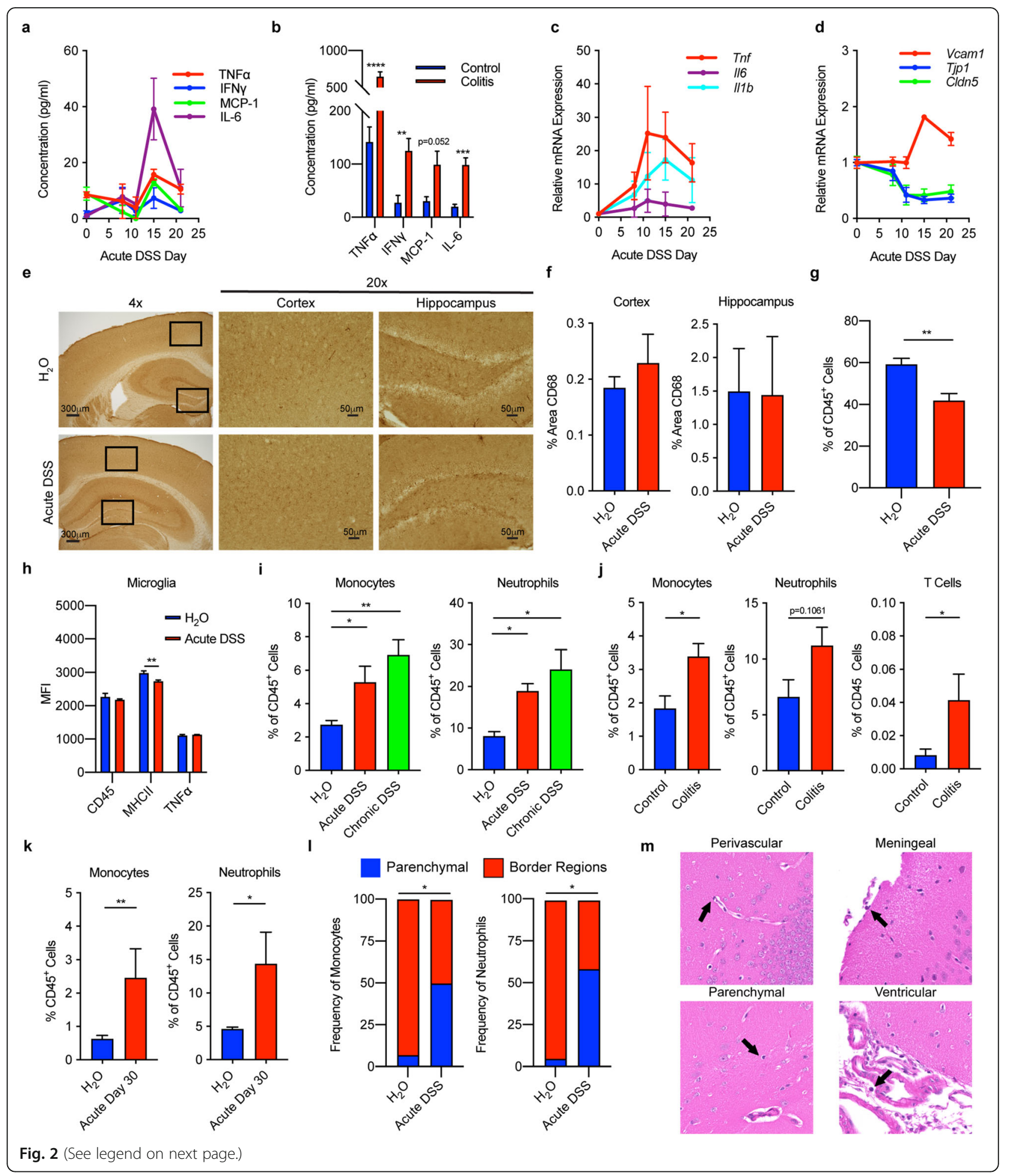


(See figure on previous page.)

Fig. 2 Colitis induces neuroinflammation with monocyte and neutrophil infiltration and increased cytokine production. a, b Plasma cytokine concentrations in mice with acute DSS-induced colitis (a) and TCT-induced colitis (b). c, d Transcription of cytokines (c), and Vcam 1, Tjp 1, and Cldn5 (d) in the brains of mice with acute DSS-induced colitis. e, $\mathbf{f}$ Representative immunohistochemistry stains (e) and quantification (f) of CD68 in hippocampal and cortex sections from mice with acute DSS-induced colitis. $\mathbf{g}$, $\mathbf{h}$ Flow cytometric analysis of microglia

$\left(\mathrm{CD} 45^{\text {lo }} \mathrm{CX} 3 \mathrm{CR} 1^{\mathrm{hi}} \mathrm{CD} 11 \mathrm{~b}^{+}\right)$showing their frequency $(\mathbf{g})$ and phenotype $(\mathbf{h})$ from mice with acute DSS-induced colitis. $\mathbf{i}$ Flow cytometric quantification of monocytes $\left(\mathrm{CD}_{4} 5^{+} \mathrm{CD} 11 \mathrm{~b}^{+} \mathrm{Ly} 6 \mathrm{G}^{-} \mathrm{Ly}_{6 \mathrm{C}} \mathrm{MHCll}^{-}\right)$and neutrophils $\left(\mathrm{CD} 45^{+} \mathrm{CD} 11 \mathrm{~b}^{+} \mathrm{Ly}_{6 \mathrm{G}}{ }^{+}\right)$in mice with acute and chronic DSSinduced colitis. $\mathbf{j}$ Flow cytometric quantification of monocytes, neutrophils, and T cells $\left(C D 45^{+} C D 11 b^{-} C D 3^{+}\right)$in mice with TCT-induced colitis. $\mathbf{k}$ Frequencies of monocytes and neutrophils 30 days following initiation of acute DSS-induced colitis. I Distribution of monocytes and neutrophils in the brains of mice with acute DSS-induced colitis. Single-cell suspensions of harvested tissue were analyzed by flow cytometry. $\mathbf{m}$ H\&E stain of brain sections from mice with acute DSS-induced colitis. $n=5-10$ mice/group, representative of 3-5 replicate experiments. ${ }^{*} p<0.05,{ }^{* *} p<0.01$, ${ }^{* * *} p<0.001,{ }^{* * * *} p<0.0001$

contrast, we observed a strong negative correlation between blood neutrophil frequency and seizure threshold in clodronate-treated mice (Fig. 3c). We then directly evaluated the role of neutrophils by administering $\alpha$ Ly6G depleting antibodies intraperitoneally from days 6 to 14 following DSS colitis induction. Control mice received equivalent doses of isotype IgG2a antibody on the same dosing schedule. Despite modest neutrophil depletion of 65\% (Supplemental Figure 3c-d), we observed a $50 \%$ rescue in seizure threshold following neutrophil depletion (Fig. 3d), demonstrating a neuropathogenic role for neutrophils. To determine the mechanism by which neutrophils contribute to colitis-induced neuronal hyperexcitability, we evaluated their production of TNF $\alpha$, which is known to enhance excitability [57-60]. Based on flow cytometric analysis, neutrophils produced more TNF $\alpha$ than blood and brain monocytes and microglia in colitic mice (Fig. 3e). Furthermore, on a per-cell basis, brain-infiltrating neutrophils produced more TNF $\alpha$ in colitic mice than in healthy mice (Fig. 3e). We assessed the role of TNF $\alpha$ in mediating neuronal hyperexcitability during colitis by administering neutralizing $\alpha$-TNF $\alpha$ antibody intraperitoneally from days 6 to 14 following DSS colitis induction. Control mice received an equivalent dose of isotype IgG1 antibody on the same dosing schedule. TNF $\alpha$ neutralization was sufficient to improve seizure threshold by $55-60 \%$ in colitic mice (Fig. 3f). These findings suggest that the pathogenic role of neutrophils in mediating neuronal hyperexcitability following acute colitis is attributable to their production of TNF $\alpha$.

\section{Deconvolution, gene expression, and pathway analysis of resected brain tissue from patients with epilepsy reveal significant overlap between neuronal hyperexcitability and inflammatory pathologies}

Having established that neutrophils and TNFa play a critical role in neuronal hyperexcitability in colitic mice, we sought to determine whether this pathophysiology might generalize to humans with neuronal hyperexcitability. Brain specimens from IBD patients are unavailable, and it is also unknown which brain regions are hyperexcitable in IBD patients, so we did not use them for this analysis. Instead, we analyzed a publicly available microarray dataset comparing hyperexcitable brain tissue resected from patients with epilepsy to histologically normal tissue from post-mortem patients with no known neurological disease [61], which enabled us to study tissue that is known to be hyperexcitable. Principal component analysis (PCA) on gene expression profiles revealed a clear separation between epileptic and healthy brain tissue (Fig. 4a). Using CIBERSORTx deconvolution [44], we identified a 2-fold enrichment of neutrophils in epileptic brain tissue compared to healthy brain tissue (Fig. 4b). Differential gene expression analysis (Fig. 4c, Supplemental Table 1) revealed that TNF, CCL3, IL1B, CCL2, and PTGS2 were among the most highly upregulated (>8-fold) genes (Fig. 4 d). CCL3 is involved in neutrophil chemotaxis, and MCP-1/CCL2 is involved in monocyte chemotaxis. PTGS2, TNF $\alpha$, and IL- $1 \beta$ are highly upregulated by inflammatory neutrophils. These findings mirror the neuroinflammatory phenotype observed in colitic mice. Finally, we used overrepresentation analysis to compare the upregulated genes to gene sets from the Kyoto Encyclopedia of Genes and Genomes (KEGG), which revealed that the majority of gene sets overrepresented in epileptic brain tissue were related to those seen in autoinflammatory diseases (including IBD), immune pathways, and infection responses (Fig. 4e, Supplemental Table 2). Gene ontology (GO) analysis confirmed an enrichment in immune pathways (Supplemental Table 3). Network analysis revealed a high level of connectivity between the majority of gene sets (Fig. 4f), suggesting that common pathways underlying many different inflammatory disorders may contribute to neuronal hyperexcitability. TNF was the most frequently occurring gene on the edges of the network (Fig. 4f, g, Supplemental Table 4), indicating that it may be a prime target for the prevention or treatment of neuronal hyperexcitability in the context of, and potentially independent of, an underlying peripheral autoinflammatory disease. 


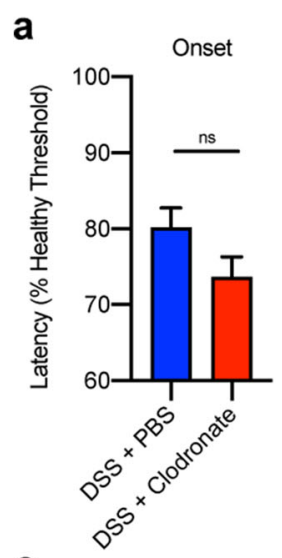

C
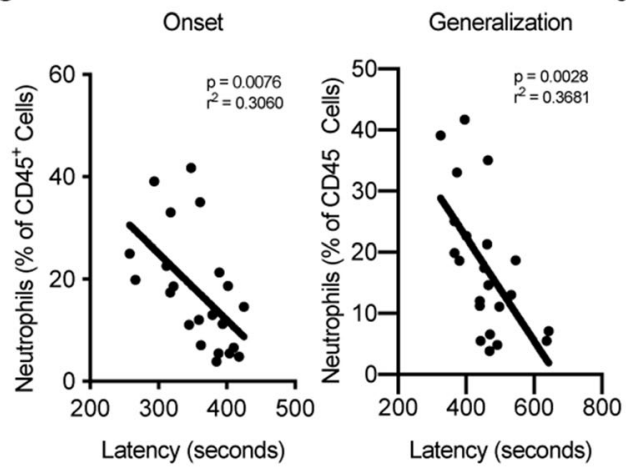

e
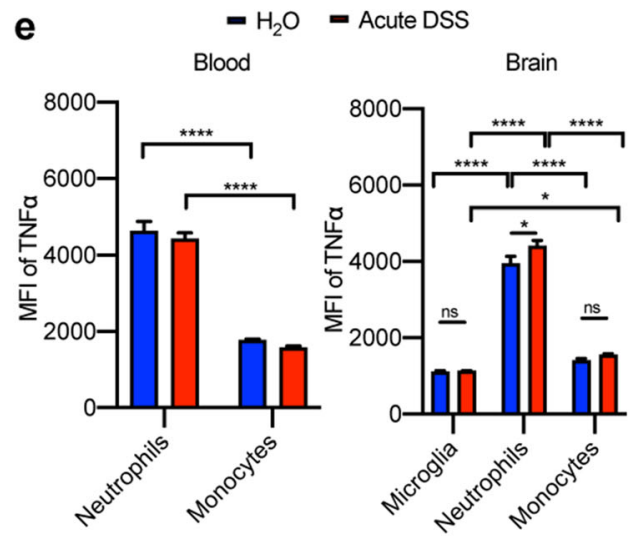

b

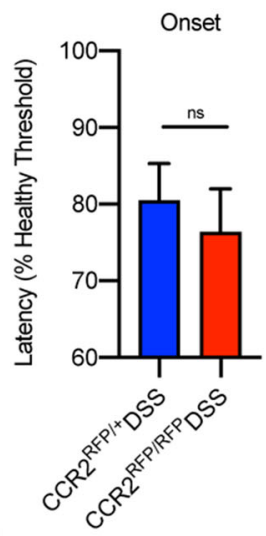

d
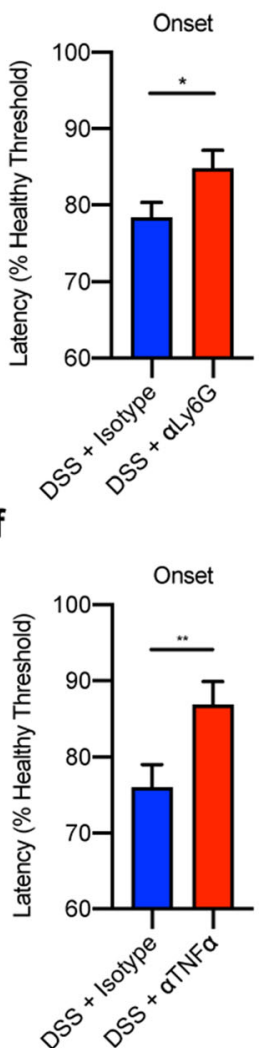
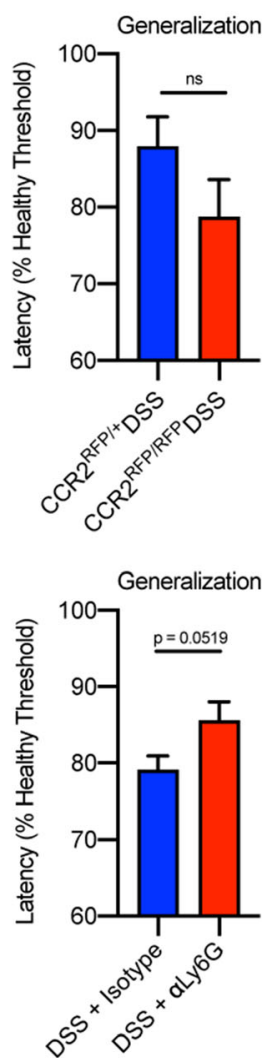

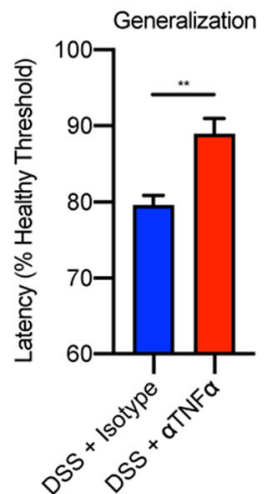

Fig. 3 Neutrophils, but not monocytes, contribute to neuronal hyperexcitability following acute colitis via TNFa. a, b Latencies to seizure onset (left) and generalization (right) in clodronate-treated mice (a) and CCR2 $2^{\text {RP/RFP }}$ mice (b) following acute DSS-induced colitis. c Linear regressions between seizure threshold and neutrophil frequencies in the blood of clodronate-treated mice following acute DSS-induced colitis. $\mathbf{d}$ Latencies to seizure onset (left) and generalization (right) in a-Ly6G-treated mice with acute DSS-induced colitis. e MFI of TNFa expressed by monocytes and neutrophils in the blood, and monocytes, neutrophils, and microglia in the brains of control mice and those with acute DSS-induced colitis. $\mathbf{f}$ Latencies to seizure onset (left) and generalization (right) in a-TNFa-treated mice following acute DSS-induced colitis. $n=8$ mice/group for flow cytometry analysis, representative of 3-5 replicate experiments. Seizure threshold data represent the combined analysis of 3-4 experiments containing 8-15 mice/condition/experiment. ns=not significant, ${ }^{*} p<0.05$, ${ }^{* *} p<0.01$, ${ }^{* * * *} p<0.0001$

\section{Discussion}

Patients with chronic inflammatory disorders frequently experience neurological symptoms related to neuronal hyperexcitability such as psychiatric disorders and epilepsy [1-7]. However, the mechanisms by which peripheral inflammation contributes to the development of these symptoms are poorly understood. Previous studies that have attempted to uncover these mechanisms have largely relied on mouse models of neurological disease, such as spontaneous seizures, neurodegeneration, 


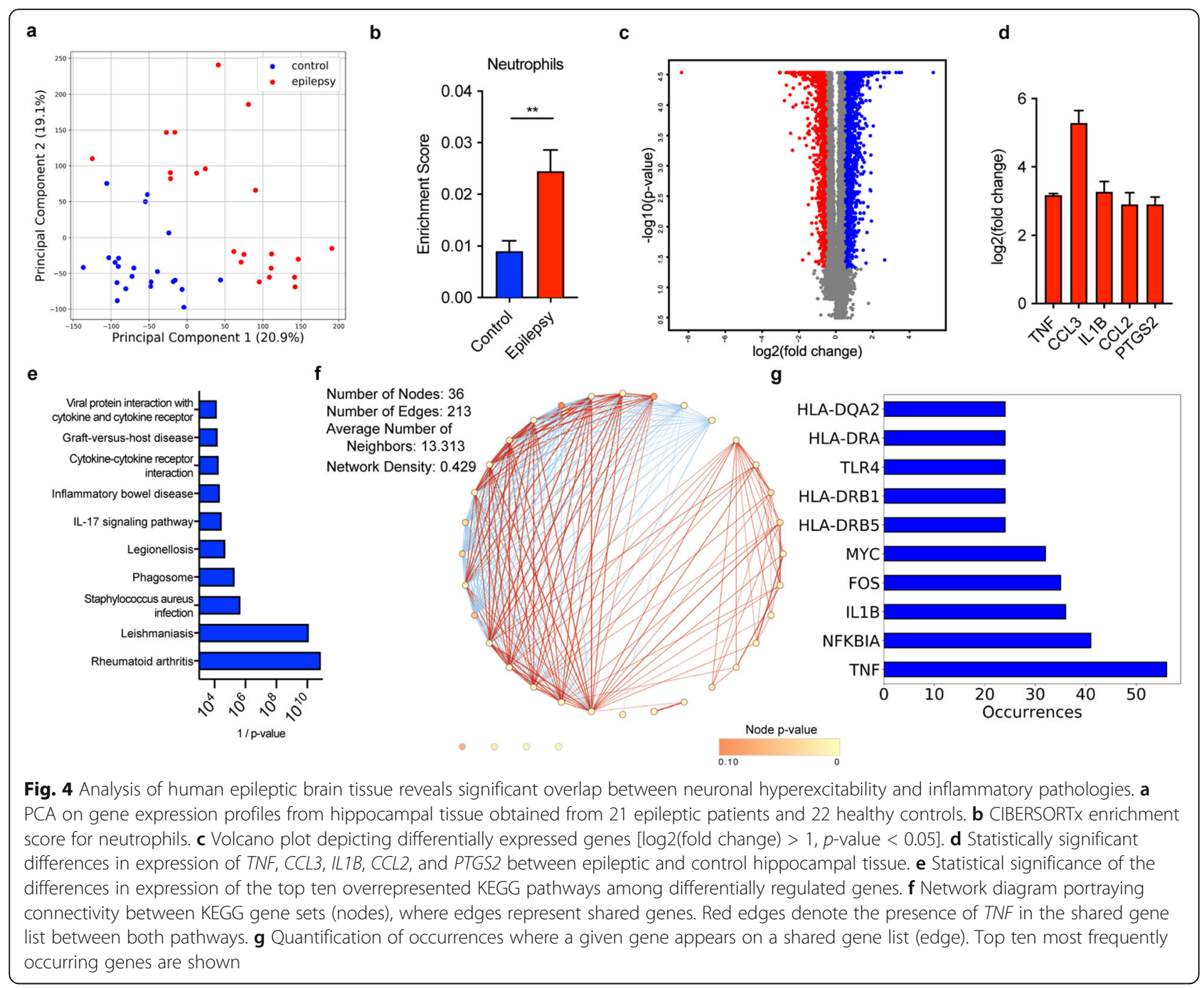

stroke, and traumatic brain injury [12-18]. These models do not allow for the uncoupling of the impact of neurological pathology on inflammation from the role of peripheral inflammation in neurological dysfunction. Other studies have utilized models of peripheral inflammation that do not closely mimic human autoinflammatory disorders, such as systemic LPS administration [19-24]. Here, we instead utilized three mouse models of colitis, as IBD has been robustly associated with neurological symptoms $[2,4,8,30-42]$. We mainly relied on the acute DSS model, as its short duration enabled mechanistic studies that would not have been feasible in the chronic models, which develop over 6-8 weeks. Nonetheless, we observed neuronal hyperexcitability in mice with chronic DSS- and TCT-induced colitis, as well as in mice with acute DSS colitis. Furthermore, we detected neuroinflammation in these mice with little to no microglia activation, as well as the presence of brain-infiltrating monocytes and neutrophils. Finally, we discovered a role for neutrophils and
TNF $\alpha$ in mediating neuronal hyperexcitability in mice with autoinflammation.

Although epithelial barrier disruption and microbial translocation play key roles in all three models of colitis, since the downstream inflammatory processes are somewhat distinct, colitis may contribute to neuroinflammation and neuronal hyperexcitability via distinct mechanisms in each model. For instance, $\mathrm{T}$ cells are not required for the induction of DSS-induced colitis, but they are the primary drivers of TCT-induced colitis [49]. While not required for induction, a T helper 1 (Th1)-polarized immune response has been observed during acute DSS-induced colitis, whereas a mixed Th1/Th2 response is seen during chronic DSS-induced colitis [49]. Conversely, Th1- and Th17-polarized responses are observed during TCT-induced colitis [49]. Despite these differences, our study showed that the peripheral inflammatory responses they generate in the brain and plasma are similar. 
While our data point to important roles of neutrophils and TNF $\alpha$ in colitis-induced neuroexcitability, other cells and inflammatory mediators likely also contribute. TNF $\alpha$ may be produced by other leukocytes during colitis, and neutrophils may produce additional factors that contribute to hyperexcitability. For instance, we observed increases in IL-1 $\beta$ and IL- 6 in the brains of colitic mice (Fig. 2c), both of which are produced by neutrophils and have been shown to exert neuroinflammatory and neuroexcitatory effects [59, 62-67]. Notably, IL-1 $\beta$ was also one of the most highly upregulated genes in the brains of patients with epilepsy (Fig. 4d). In addition to the production of neuroexcitatory cytokines, neutrophils may contribute indirectly to neuronal hyperexcitability by producing chemokines to recruit other inflammatory cells. Both CCL2 and CCL3, which were highly upregulated in epileptic brain tissue (Fig. 4d), are produced by neutrophils and participate in the recruitment of monocytes and other bone marrow-derived cells. Indeed, the CCL2/CCR2 axis has previously been implicated in inflammation-induced seizure enhancement [17]. Additionally, our studies do not determine whether neutrophils, TNF $\alpha$, or other mediators are acting exclusively in the brain parenchyma, or whether their effects on vascular tissue and interactions with the enteric nervous system and/or vagus nerve may also be contributing to hyperexcitability. Finally, it is possible that other cells, including microglia, may be involved in spite of the lack of evidence for this in our experiments. Future studies investigating additional mechanisms by which colitis induces neuronal hyperexcitability are necessary for a more complete understanding of the pathological effects of the gut and other forms of peripheral inflammation on neuroinflammation and neuronal dysregulation.

Although it is unlikely that neutrophils and TNF $\alpha$ are the sole mediators of neuronal hyperexcitability in the setting of inflammatory disease, our findings suggest that TNF $\alpha$ blocking agents may be beneficial for the large number of patients with such disorders who experience neurological and psychiatric symptoms. TNF $\alpha$ enhances excitability by increasing glutamate release, regulating AMPA cell surface trafficking to enhance glutamate responses, and causing endocytosis of $\mathrm{GABA}_{\mathrm{A}}$ receptors [57-60]. It also activates vascular endothelial cells [68, 69] and impairs BBB integrity [70, 71], both of which contribute to neuroinflammation. Furthermore, TNF $\alpha$ inhibition has been shown to improve the sense of wellbeing, sensory function, and cognitive processing in patients with IBD [72]. Because neuroinflammation occurs in many neurological and psychiatric disorders in the absence of a diagnosed inflammatory condition [25-29], TNF $\alpha$ inhibitors may also prove efficacious in patients without an underlying autoinflammatory disease. Indeed, TNF $\alpha$ has been implicated in major depressive disorder but has not yet been evaluated therapeutically in patients with this disorder [73]. Nonetheless, further studies are essential for understanding the mechanisms by which TNF $\alpha$ contributes to neuronal hyperexcitability in the context of colitis, as TNF $\alpha$ inhibition has in some cases been associated with enhanced excitability and neurodegeneration, especially in the context of demyelinating disorders [59, 63, 74]. Differences between the central and peripheral functions of TNF $\alpha$, as well as signaling via TNF receptor 1 (TNFR1) versus TNFR2, may be responsible for the contrasting roles of TNF $\alpha$ in different neurological diseases $[59,63,74]$.

While our studies reveal a mechanism by which intestinal inflammation results in neuronal hyperexcitability, future studies examining the neuroinflammatory phenotype of mice with other models of autoinflammation such as rheumatoid arthritis or diabetes would be beneficial for understanding whether there is overlap in the mechanisms by which peripheral inflammation contributes to neurological dysfunction, or whether neurological symptoms in different autoimmune disorders are the result of processes specific to each disease. Our gene expression and pathway analysis of human epileptic brain tissue suggests that hyperexcitability of diverse etiology may result from similar inflammatory mechanisms, as the transcriptional signature of hyperexcitable brain tissue had significant overlap with gene sets associated with autoinflammatory disorders. Furthermore, there was a high level of connectivity between the vast majority of these gene sets, indicating that pathways common to a large number of autoinflammatory disorders may contribute to neuronal hyperexcitability, rather than each disorder causing neurological dysfunction via a unique mechanism. TNF $\alpha$ was the highest occurring gene on the edges of the network, highlighting its important role in immune pathologies associated with neurological dysfunction.

\section{Conclusions}

Our results reveal neutrophils and TNF $\alpha$ as central regulators of neuronal hyperexcitability of diverse etiology. Since existing treatments for neurological disorders largely target neurons and not inflammation, these treatments therefore fail to address this component. Furthermore, these drugs have serious side effect profiles, and many patients are unresponsive to them. Because treatments targeting inflammatory mediators do not directly target neuronal function but may address a major component of the underlying pathology, such treatments would be expected to have superior efficacy as well as side effect profiles. Thus, there is a strong rationale for evaluating anti-inflammatory agents, including TNFo inhibitors, for the treatment of neurological and psychiatric symptoms present in, and potentially independent of, a diagnosed inflammatory disorder. 


\section{Abbreviations}

DSS: Dextran sodium sulfate; GABA: y-Aminobutyric acid; GO: Gene ontology; IBD: Inflammatory bowel disease; LPS: Lipopolysaccharide; PCA: Principal component analysis; TCT: T cell transfer

\section{Supplementary Information}

The online version contains supplementary material available at https://doi. org/10.1186/s12974-021-02262-4

Additional file 1: Supplemental Figure 1. Linear regressions between cytokine transcription and Tjp1 and Cldn5. $n=5-10$ mice/group, representative of 3-5 replicate experiments. Supplemental Figure 2. Frequencies of immune cell populations in the brains of mice following acute DSS-

induced colitis. Flow cytometric quantification of a) macrophages $\left.\left(\mathrm{CD}_{4}{ }^{+} \mathrm{CD} 11 \mathrm{~b}^{+} \mathrm{Ly}_{6 \mathrm{G}}^{-} \mathrm{Ly}_{6} \mathrm{C}^{-} \mathrm{MHCl}{ }^{+}\right), \mathbf{b}\right)$ dendritic cells

$\left.\left(\mathrm{CD}_{4} 5^{+} \mathrm{CD} 11 \mathrm{~b}^{+} \mathrm{Ly}_{6 \mathrm{G}}^{-} \mathrm{CD} 11 \mathrm{c}^{+}\right), \mathbf{c}\right) \mathrm{B}$ cells $\left(\mathrm{CD}_{4} 5^{+} \mathrm{CD} 11 \mathrm{~b}^{-} \mathrm{CD}^{-} \mathrm{CD} 19^{+}\right)$, and $\left.\mathbf{d}\right)$ T cells $\left(\mathrm{CD}_{4} 5^{+} \mathrm{CD} 11 \mathrm{~b} \mathrm{CD}^{+}\right) \cdot n=5-10$ mice/group, representative of 3-5 replicate experiments. ns $=$ not significant, ${ }^{*} p<0.05$. Supplemental Figure 3. Depletion efficiency of monocytes and neutrophils in mice following acute DSS-induced colitis. a-b) $200 \mathrm{~mL}$ of clodronate-loaded liposomes was administered on days 6-14 during acute DSS-induced colitis. a) Flow cytometric quantification of monocytes (CD45+CD11 b ${ }^{+} \mathrm{Ly} 6-$ $\mathrm{G}^{-} \mathrm{Ly} 6 \mathrm{C}^{+} \mathrm{MHCII}^{-}$) in colitic mouse blood following clodronate treatment. b) Percent of monocytes in colitic mouse blood following clodronate treatment normalized to the mean percent of monocytes in colitic mice treated with PBS-loaded liposomes. c-d) 500mg a-Ly6G antibody was administered on days 6-14 during acute DSS-induced colitis induction. c) Flow cytometric quantification of neutrophils $\left(\mathrm{CD} 45^{+} \mathrm{CD} 11 \mathrm{~b}^{+} \mathrm{Ly} 6 \mathrm{G}^{+}\right)$in colitic mouse blood following a-Ly6G antibody treatment. d) Percent of neutrophils in colitic mouse blood following a-Ly6G antibody treatment normalized to the mean percent of neutrophils in colitic mice treated with isotype lgG2a antibody. Data are representative of 3-4 combined experiments with 5-15 mice/group/experiment. ${ }^{*} p<0.05$, ${ }^{* * *} p<0.0001$. Supplemental Figure 4. Representative images of in vivo a-CD45 staining of border-associated immune cells. a) Immunofluorescence images of the choroid plexus in healthy and colitic mice following in vivo staining of border regions with an a-CD45 antibody and subsequent ex vivo aCD45 staining of all leukocytes. Parenchymal cells (i.e. microglia) do not stain positive for the in vivo-administered a-CD45, but border-associated cells (i.e. those in the choroid plexus) stain for both the in vivo- and ex vivo-administered a-CD45. b) Representative flow cytometry plots of in vivo- and ex vivo-administered a-CD45 staining of microglia $\left(\mathrm{CD} 45^{\text {lo }} \mathrm{CX} 3 \mathrm{CR} 1^{\text {hi }} \mathrm{CD} 11 \mathrm{~b}^{+}\right)$and neutrophils $\left(\mathrm{CD} 45^{+} \mathrm{CD} 11 \mathrm{~b}^{+} \mathrm{Ly}_{6 \mathrm{G}}{ }^{+}\right)$in the brains of healthy and colitic mice. Microglia (parenchymal cells) are not stained by the in vivo-administered a-CD45 in either condition. $031821 \mathrm{~J}$ Neuroinflammation Tables.pdf. Supplementary Tables.

\section{Acknowledgements}

The authors would like to acknowledge the intellectual contributions of Nathan Reticker-Flynn, PhD; lan Linde, PhD; Robert Yuan, PhD; Nichole Escalante, PhD; Yoni Rubin, PhD; Sameera Kongara, PhD; Aida Habtezion, MD, MSc; and Sean Bendall, PhD. We thank Nathan Reticker-Flynn for providing his expertise in systems biology and computational methods. We thank lan Linde for providing his expertise in neutrophil and TNFa biology. We thank Robert Yuan, Nichole Escalante, and Aida Habtezion for providing their expertise in inflammatory bowel disease and mouse colitis models. We thank Sean Bendall for providing his expertise in systems immunology. We thank Yoni Rubin and Sameera Kongara for their review of the manuscript. Finally, we thank the members of the Stanford Blood Center Flow Cytometry Core: Lorna Tolentino, Okmi Choi, and Nancy Wu.

\section{Authors' contributions}

SEB conceived of this work, completed most experimental procedures, and wrote the manuscript. KAZ performed immunohistochemistry stains and analysis and provided her expertise on neuroinflammatory processes. GTI aided in several experimental procedures and participated in the computational analysis of human resected brain tissue. MSB provided resources for immunohistochemistry, as well as advice and expertise on neuroinflammatory processes. EGE supervised the work and provided resources for the majority of experiments in this study. All authors participated in the writing and editing of this manuscript. The authors read and approved the final manuscript.

\section{Funding}

This research was funded by the Charles Hsiao Fund (EGE), the Frontiers in Brain Health Award from AHA/Paul Allen Foundation 19PABHI34580007 (MSB), and the Leduca Stroke-IMPaCT Transatlantic Network of Excellence (MSB). Sarah E. Barnes and Geoffrey T. Ivison are supported by the NIH training grant T32Al007290. Kristy A. Zera was supported by the Alzheimer's Association Research Fellowship AARF-20-685030.

\section{Availability of data and materials}

All data generated and analyzed during this study are included in this published article and its supplementary information. The public microarray dataset from resected brain tissue from human epilepsy patients is available in the ArrayExpress repository: https://www.ebi.ac.uk/arrayexpress/ experiments/E-MTAB-3123/

\section{Declarations}

\section{Ethics approval and consent to participate}

All animal protocols used in this study were approved by the Stanford University Institutional Animal Care and Use Committee.

\section{Consent for publication}

Not applicable.

\section{Competing interests}

The authors declare that they have no competing interests.

\section{Author details}

${ }^{1}$ Department of Pathology, Stanford University, Stanford, CA, USA.

2Department of Neurology, Stanford University, Stanford, CA, USA.

${ }^{3}$ Department of Infectious Diseases, Stanford University, Stanford, CA, USA.

Received: 29 March 2021 Accepted: 30 August 2021

Published online: 12 September 2021

\section{References}

1. Cullen AE, Holmes S, Pollak TA, Blackman G, Joyce DW, Kempton MJ, et al. Associations between non-neurological autoimmune disorders and psychosis: a meta-analysis. Biol Psychiatry. 2019;85(1):35-48. https://doi.org/1 0.1016/j.biopsych.2018.06.016.

2. Devinsky O, Schein A, Najjar S. Epilepsy associated with systemic autoimmune disorders. Epilepsy Curr. 2013;13(2):62-8. https://doi.org/10. 5698/1535-7597-13.2.62.

3. Kayser MS, Dalmau J. The emerging link between autoimmune disorders and neuropsychiatric disease. J Neuropsychiatry Clin Neurosci. 2011;23(1): 90-7. https://doi.org/10.1176/appi.neuropsych.23.1.90.

4. $\quad$ Lin Z, Si Q, Xiaoyi Z. Association between epilepsy and systemic autoimmune diseases: a meta-analysis. Seizure. 2016;41:160-6. https://doi. org/10.1016/j.seizure.2016.08.003.

5. Schor NF. Neurology of systemic autoimmune disorders: a pediatric perspective. Semin Pediatr Neurol. 2000;7(2):108-17. https://doi.org/10.1053/ pb.2000.6692

6. Valencia I. Epilepsy in systemic autoimmune disorders. Semin Pediatr Neurol. 2014;21(3):226-31. https://doi.org/10.1016/j.spen.2014.07.001.

7. Vincent A, Crino PB. Systemic and neurologic autoimmune disorders associated with seizures or epilepsy. Epilepsia. 2011;52(Suppl 3):12-7. https://doi.org/10.1111/j.1528-1167.2011.03030.x.

8. Ong M-S, Kohane IS, Cai T, Gorman MP, Mandl KD. Population-level evidence for an autoimmune etiology of epilepsy. JAMA Neurol. 2014;71(5): 569-74. https://doi.org/10.1001/jamaneurol.2014.188.

9. Hilt RJ, Chaudhari M, Bell JF, Wolf C, Koprowicz K, King BH. Side effects from use of one or more psychiatric medications in a population-based sample of children and adolescents. J Child Adolesc Psychopharmacol. 2014;24(2): 83-9. https://doi.org/10.1089/cap.2013.0036.

10. Haddad PM, Dursun SM. Neurological complications of psychiatric drugs: clinical features and management. Hum Psychopharmacol. 2008:23(Suppl 1): 15-26. https://doi.org/10.1002/hup.918. 
11. Hayter SM, Cook MC. Updated assessment of the prevalence, spectrum and case definition of autoimmune disease. Autoimmun Rev. 2012;11(10):75465. https://doi.org/10.1016/j.autrev.2012.02.001.

12. Riazi K, Galic MA, Kuzmiski JB, Ho W, Sharkey KA, Pittman QJ. Microglial activation and TNFa production mediate altered CNS excitability following peripheral inflammation. Proc Nat Acad Sci. 2008;105(44):17151-6. https:// doi.org/10.1073/pnas.0806682105.

13. Riazi $\mathrm{K}$, Honar H, Homayoun H, Demehri S, Bahadori M, Dehpour AR. Intestinal inflammation alters the susceptibility to pentylenetetrazoleinduced seizure in mice. J Gastroenterol Hepatol. 2004;19(3):270-7. https:// doi.org/10.1111/j.1440-1746.2003.03284.x.

14. D'Mello C, Riazi K, Le T, Stevens KM, Wang A, McKay DM, et al. P-selectinmediated monocyte-cerebral endothelium adhesive interactions link peripheral organ inflammation to sickness behaviors. J Neurosci. 2013; 33(37):14878-88. https://doi.org/10.1523/JNEUROSCI.1329-13.2013.

15. Buckman LB, Thompson MM, Moreno HN, Ellacott KLJ. Regional astrogliosis in the mouse hypothalamus in response to obesity. J Comp Neurol. 2013; 521(6):1322-33. https://doi.org/10.1002/cne.23233.

16. Buckman LB, Hasty AH, Flaherty DK, Buckman CT, Thompson MM, Matlock BK, et al. Obesity induced by a high-fat diet is associated with increased immune cell entry into the central nervous system. Brain Behav Immun. 2014;35:33-42. https://doi.org/10.1016/j.bbi.2013.06.007.

17. Cerri C, Genovesi S, Allegra M, Pistillo F, Püntener U, Guglielmotti A, et al. The chemokine CCL2 mediates the seizure-enhancing effects of systemic inflammation. J Neurosci. 2016;36(13):3777-88. https://doi.org/10.1523/ JNEUROSCI.0451-15.2016

18. D'Mello C, Le T, Swain MG. Cerebral microglia recruit monocytes into the brain in response to tumor necrosis factoralpha signaling during peripheral organ inflammation. J Neurosci. 2009;29(7):2089-102. https://doi.org/10.1 523/JNEUROSCI.3567-08.2009.

19. Auvin S, Shin D, Mazarati A, Sankar R. Inflammation induced by LPS enhances epileptogenesis in immature rat and may be partially reversed by IL1RA. Epilepsia. 2010;51(Suppl 3):34-8. https://doi.org/10.1111/j.1528-1167.2 010.02606.x

20. Cai Z, Pang $Y$, Lin S, Rhodes PG. Differential roles of tumor necrosis factor-a and interleukin-1 $\beta$ in lipopolysaccharide-induced brain injury in the neonatal rat. Brain Res. 2003;975(1-2):37-47. https://doi.org/10.1016/S00068993(03)02545-9.

21. Galic MA, Riazi K, Heida JG, Mouihate A, Fournier NM, Spencer SJ, et al. Postnatal inflammation increases seizure susceptibility in adult rats. J Neurosci. 2008;28(27):6904-13. https://doi.org/10.1523/JNEUROSCI.190108.2008 .

22. Jeong H-K, Jou I. Joe E-h: Systemic LPS administration induces brain inflammation but not dopaminergic neuronal death in the substantia nigra. Exp Mol Med. 2010;42(12):823-32. https://doi.org/10.3858/emm.2 010.42 .12 .085

23. Kołosowska K, Maciejak P, Szyndler J, Turzyńska D, Sobolewska A, Płaźnik A The role of IL-1 $\beta$ and glutamate in the effects of lipopolysaccharide on the hippocampal electrical kindling of seizures. J Neuroimmunol. 2016;298:14652. https://doi.org/10.1016/j.jneuroim.2016.07.018.

24. Qin L, Wu X, Block ML, Liu Y, Breese GR, Hong J-S, et al. Systemic LPS causes chronic neuroinflammation and progressive neurodegeneration. Glia. 2007; 55(5):453-62. https://doi.org/10.1002/glia.20467.

25. Das M, Mohapatra S, Mohapatra SS. New perspectives on central and peripheral immune responses to acute traumatic brain injury. J Neuroinflammation. 2012;9(1):236. https://doi.org/10.1186/1742-2094-9-236.

26. Niesman IR, Schilling JM, Shapiro LA, Kellerhals SE, Bonds JA, Kleschevnikov AM, et al. Traumatic brain injury enhances neuroinflammation and lesion volume in caveolin deficient mice. J Neuroinflammation. 2014;11(1):39. https://doi.org/10.1186/1742-2094-11-39.

27. Simon DW, McGeachy MJ, Bayır H, Clark RSB, Loane DJ, Kochanek PM. The far-reaching scope of neuroinflammation after traumatic brain injury. Nat Rev Neurol. 2017;13(3):171-91. https://doi.org/10.1038/nrneurol.2017.13.

28. Stilling RM, Cryan JF. Host response: a trigger for neurodegeneration? Nature Microbiology. 2016;1(8):16129. https://doi.org/10.1038/nmicrobiol.2016.129.

29. Dickens AM, Tovar-y-Romo LB, Yoo S-W, Trout AL, Bae M, Kanmogne M, et al. Astrocyte-shed extracellular vesicles regulate the peripheral leukocyte response to inflammatory brain lesions. Sci Signal. 2017;10:eaai7696.

30. Benavente L, Morís $G$. Neurologic disorders associated with inflammatory bowel disease. Eur J Neurol. 2011;18(1):138-43. https://doi.org/10.1111/j.14 68-1331.2010.03095.x.
31. Kappelman MD, Moore KR, Allen JK, Cook SF. Recent trends in the prevalence of Crohn's disease and ulcerative colitis in a commercially insured US population. Dig Dis Sci. 2013;58(2):519-25. https://doi.org/10.1 007/s10620-012-2371-5.

32. Langenberg DRV, Yelland GW, Robinson SR, Gibson PR. Cognitive impairment in Crohn's disease is associated with systemic inflammation, symptom burden and sleep disturbance. U Eur Gastroenterol J. 2017;5(4): 579-87. https://doi.org/10.1177/2050640616663397.

33. Loftus EV Jr. Clinical epidemiology of inflammatory bowel disease: incidence, prevalence, and environmental influences. Gastroenterology. 2004;126(6):1504-17. https://doi.org/10.1053/j.gastro.2004.01.063.

34. Virta $L$, Kolho K-L. The risk of contracting pediatric inflammatory bowel disease in children with celiac disease, epilepsy, juvenile arthritis and type 1 diabetes - a nationwide study. J Crohns Colitis. 2013;7(1):53-7. https://doi. org/10.1016/j.crohns.2012.02.021

35. Camara-Lemarroy CR, Escobedo-Zúñiga N, Ortiz-Zacarias D, Peña-Avendaño J. Villarreal-Garza E, Díaz-Torres MA. Prevalence and impact of irritable bowe syndrome in people with epilepsy. Epilepsy Behav. 2016;63:29-33. https:// doi.org/10.1016/j.yebeh.2016.05.041.

36. Chapman RW, Laidlow JM, Colin-Jones D, Eade OE, Smith CL. Increased prevalence of epilepsy in coeliac disease. Br Med J. 1978;2(6132):250-1. https://doi.org/10.1136/bmj.2.6132.250.

37. Tellez-Zenteno JF, Matijevic S, Wiebe S. Somatic comorbidity of epilepsy in the general population in Canada. Epilepsia. 2005;46(12):1955-62. https:// doi.org/10.1111/j.1528-1167.2005.00344.x.

38. Hermaszewski RA, Rigby S, Dalgleish AG. Coeliac disease presenting with cerebellar degeneration. Postgrad Med J. 1991;67(793):1023-4. https://doi. org/10.1136/pgmj.67.793.1023.

39. Luostarinen L, Pirttilä T, Collin P. Coeliac disease presenting with neurological disorders. Eur Neurol. 1999;42(3):132-5. https://doi.org/10.1159/ 000008086.

40. Mirabella M, Cianfoni A, Bucci M, Nociti V, Sancricca C, Patanella AK, et al. Coeliac disease presenting with acute disseminated encephalomyelitis. Eur $J$ Neurol. 2006;13(2):202-3. https://doi.org/10.1111/j.1468-1331.2006.01112.x.

41. Oliveira-Maia AJ, Andrade I, Barahona-Corrêa JB. Case of coeliac disease presenting in the psychiatry ward. BMJ Case Rep. 2016;2016. https://doi. org/10.1136/bcr-2016-216825.

42. Scheid R, Teich N. Neurologic manifestations of ulcerative colitis. Eur J Neurol. 2007;14(5):483-93. https://doi.org/10.1111/j.1468-1331.2007.01718.x

43. Tusher VG, Tibshirani R, Chu G. Significance analysis of microarrays applied to the ionizing radiation response. Proc Natl Acad Sci U S A. 2001;98(9): 5116-21. https://doi.org/10.1073/pnas.091062498.

44. Newman AM, Steen CB, Liu CL, Gentles AJ, Chaudhuri AA, Scherer F, et al. Determining cell type abundance and expression from bulk tissues with digital cytometry. Nat Biotechnol. 2019;37(7):773-82. https://doi.org/10.1038/ s41587-019-0114-2.

45. Pedregosa F, Varoquaux G, Gramfort A, Michel V, Thirion B, Grisel O, et al. Scikit-learn: machine learning in Python. J Mach Learn Res. 2011;12:2825-30.

46. Kuleshov MV, Jones MR, Rouillard AD, Fernandez NF, Duan Q, Wang Z, et al. Enrichr: a comprehensive gene set enrichment analysis web server 2016 update. Nucleic Acids Res. 2016;44(W1):W90-7. https://doi.org/10.1093/nar/ gkw377.

47. Chen EY, Tan CM, Kou Y, Duan Q, Wang Z, Meirelles GV, et al. Enrichr: interactive and collaborative HTML5 gene list enrichment analysis tool. BMC Bioinformatics. 2013:14(1):128. https://doi.org/10.1186/1471-2105-14-128.

48. Shannon P, Markiel A, Ozier O, Baliga NS, Wang JT, Ramage D, et al. Cytoscape: a software environment for integrated models of biomolecular interaction networks. Genome Res. 2003;13(11):2498-504. https://doi.org/1 $0.1101 /$ gr. 1239303

49. Kiesler P, Fuss IJ, Strober W. Experimental models of inflammatory bowel diseases. Cell Mol Gastroenterol Hepatol. 2015;1(2):154-70. https://doi.org/1 0.1016/j.jcmgh.2015.01.006

50. Kitajima S, Takuma S, Morimoto M. Tissue distribution of dextran sulfate sodium (DSS) in the acute phase of murine DSS-induced colitis. J Vet Med Sci. 1999;61(1):67-70. https://doi.org/10.1292/jvms.61.67.

51. Prichahd JW, Gallagher BB, Glaser GH. Experimental seizure-threshold testing with flurothyl. J Pharmacol Exp Ther. 1969;166:170-8

52. Remington LT, Babcock AA, Zehntner SP, Owens T. Microglial recruitment, activation, and proliferation in response to primary demyelination. Am J Pathol. 2007;170(5):1713-24. https://doi.org/10.23 53/ajpath.2007.060783. 
53. Readnower RD, Chavko M, Adeeb S, Conroy MD, Pauly JR, McCarron RM, et al. Increase in blood-brain barrier permeability, oxidative stress, and activated microglia in a rat model of blast-induced traumatic brain injury. Neurosci Res. 2010;88(16):3530-9. https://doi.org/10.1002/jnr.22510.

54. Pascual O, Achour SB, Rostaing P, Triller A, Bessis A. Microglia activation triggers astrocyte-mediated modulation of excitatory neurotransmission. Proc Natl Acad Sci. 2012;109(4):E197-205. https://doi.org/10.1073/pnas.1111 098109.

55. Mrdjen D, Pavlovic A, Hartmann FJ, Schreiner B, Utz SG, Leung BP, et al. High-dimensional single-cell mapping of central nervous system immune cells reveals distinct myeloid subsets in health, aging, and disease. Immunity. 2018;48:380-395.e386.

56. Hernandez-Ontiveros DG, Tajiri N, Acosta S, Giunta B, Tan J, Borlongan CV. Microglia activation as a biomarker for traumatic brain injury. Front Neurol. 2013;4. https://doi.org/10.3389/fneur.2013.00030.

57. Iori V, Frigerio F, Vezzani A. Modulation of neuronal excitability by immune mediators in epilepsy. Curr Opin Pharmacol. 2016;26:118-23. https://doi. org/10.1016/j.coph.2015.11.002.

58. Riazi K, Galic MA, Pittman QJ. Contributions of peripheral inflammation to seizure susceptibility: cytokines and brain excitability. Epilepsy Res. 2010; 89(1):34-42. https://doi.org/10.1016/j.eplepsyres.2009.09.004.

59. Vezzani A, Balosso S, Ravizza T. The role of cytokines in the pathophysiology of epilepsy. Brain Behav Immun. 2008;22(6):797-803. https://doi.org/10.1016/ j.bbi.2008.03.009.

60. Woods C, Marques-Lopes J, Contoreggi NH, Milner TA, Pickel VM, Wang G, et al. Tumor necrosis factor alpha-receptor type 1 activation in the hypothalamic paraventricular nucleus contributes to glutamate signaling and angiotensin II-dependent hypertension. J Neurosci. 2020;41(6):1349-62. https://doi.org/10.1523/JNEUROSCI.2360-19.2020.

61. Mirza N. Gene expression analysis of hippocampal tissue from epilepsy surgery. 1 edition. https://www.ebi.ac.uk/arrayexpress/experiments/E-MTA B-3123: ArrayExpress; 2015

62. Wang $Y$, Jin S, Sonobe $Y$, Cheng $Y$, Horiuchi $H$, Parajuli B, et al. Interleukin-1 $\beta$ induces blood-brain barrier disruption by downregulating sonic hedgehog in astrocytes. PLoS One. 2014;9(10):e1 10024. https://doi.org/10.1371/journal. pone.0110024.

63. Vezzani A, Moneta D, Richichi C, Aliprandi M, Burrows SJ, Ravizza T, et al. Functional role of inflammatory cytokines and antiinflammatory molecules in seizures and epileptogenesis. Epilepsia. 2002;43(Suppl 5):30-5. https://doi. org/10.1046/j.1528-1157.43.s.5.14.x.

64. Peltola J, Hurme M, Miettinen A, Keränen T. Elevated levels of interleukin-6 may occur in cerebrospinal fluid from patients with recent epileptic seizures. Epilepsy Res. 1998;31(2):129-33. https://doi.org/10.1016/S0920-1211 (98)00024-2.

65. Dubé C, Vezzani A, Behrens M, Bartfai T, Baram TZ. Interleukin-1 $\beta$ contributes to the generation of experimental febrile seizures. Ann Neurol. 2005;57(1):152-5. https://doi.org/10.1002/ana.20358.

66. Campbell IL, Abraham CR, Masliah E, Kemper P, Inglis JD, Oldstone MB, et al. Neurologic disease induced in transgenic mice by cerebral overexpression of interleukin 6. Proc Natl Acad Sci U S A. 1993;90(21):10061-5. https://doi. org/10.1073/pnas.90.21.10061

67. Argaw AT, Zhang Y, Snyder BJ, Zhao M-L, Kopp N, Lee SC, et al. IL-1 beta regulates blood-brain barrier permeability via reactivation of the hypoxiaangiogenesis program. J Immunol (Baltimore, Md: 1950). 2006;177:5574-84.

68. Min JK, Kim YM, Kim SW, Kwon MC, Kong YY, Hwang IK, et al. TNF-related activation-induced cytokine enhances leukocyte adhesiveness: induction of ICAM-1 and VCAM-1 via TNF receptor-associated factor and protein kinase C-dependent NF-kappaB activation in endothelial cells. J Immunol. 2005; 175(1):531-40. https://doi.org/10.4049/jimmunol.175.1.531.

69. McHale JF, Harari OA, Marshall D, Haskard DO. TNF-alpha and IL-1 sequentially induce endothelial ICAM-1 and VCAM-1 expression in MRL/Ipr lupus-prone mice. J Immunol. 1999;163:3993-4000.

70. Rochfort KD, Collins LE, Murphy RP, Cummins PM. Downregulation of blood-brain barrier phenotype by proinflammatory cytokines involves NADP $\mathrm{H}$ oxidase-dependent ROS generation: consequences for interendothelial adherens and tight junctions. PLoS One. 2014;9(7):e101815. https://doi.org/1 0.1371/journal.pone.0101815.

71. de Vries HE, Blom-Roosemalen MCM, Oosten MV, de Boer AG, van Berkel TJC, Breimer DD, et al. The influence of cytokines on the integrity of the blood-brain barrier in vitro. J Neuroimmunol. 1996;64(1):37-43. https://doi. org/10.1016/0165-5728(95)00148-4.
72. Gray MA, Chao CY, Staudacher HM, Kolosky NA, Talley NJ, Holtmann G. AntiTNFa therapy in IBD alters brain activity reflecting visceral sensory function and cognitive-affective biases. PLoS One. 2018;13(3):e0193542. https://doi. org/10.1371/journal.pone.0193542.

73. Bortolato B, Carvalho AF, Soczynska JK, Perini Gl, Mclntyre RS. The involvement of TNF-a in cognitive dysfunction associated with major depressive disorder: an opportunity for domain specific treatments. Curr Neuropharmacol. 2015;13(5):558-76. https://doi.org/10.2174/1570159X13 666150630171433

74. Kemanetzoglou E, Andreadou E. CNS demyelination with TNF-a blockers. Curr Neurol Neurosci Rep. 2017;17(4):36. https://doi.org/10.1007/s11910-0170742-1.

\section{Publisher's Note}

Springer Nature remains neutral with regard to jurisdictional claims in published maps and institutional affiliations.
Ready to submit your research? Choose BMC and benefit from:

- fast, convenient online submission

- thorough peer review by experienced researchers in your field

- rapid publication on acceptance

- support for research data, including large and complex data types

- gold Open Access which fosters wider collaboration and increased citations

- maximum visibility for your research: over $100 \mathrm{M}$ website views per year

At BMC, research is always in progress.

Learn more biomedcentral.com/submissions 